\title{
PROTOTYPE ROBOT CERDAS PEMOTONG RUMPUT BERBASIS RASPBERRY Pi B+ MENGGUNAKAN WEB BROWSER
}

\author{
Diah Aryani ${ }^{1}$ \\ Muhamad Wahyudin ${ }^{2}$ \\ Muhammad Fazri ${ }^{3}$ \\ e-mail:diah.aryani@raharja.info,wahyudin@raharja.info,fazri@raharja.info
}

\begin{abstract}
ABSTRAK
Saat ini ilmu pengetahuan dan teknologi sedang berkembang pesat sehingga memberikan manfaat besar dalam segala aspek kehidupan manusia salah satunya yaitu robot-robot yang dirancang untuk dapat membantu tugas-tugas manusia melalui pengawasan dan kontrol manusia, ataupun menggunakan program. Perkembangan rumput yang merambat tanah dengan cepat sering membuat perawat taman harus intensif memotong rumput dengan teratur. Berkaitan dengan hal tersebut, maka dibuatlah alat berupa robot cerdas pemotong rumput berbasis raspberry Pi B+ merupakan penerapan sistem robotik yang bertujuan mengendalikan 2 buah motor Driver $1298 n$ yang berguna untuk menjalankan gear box roda robot dan dinamo pemotong rumput pada alat pemotong rumput tanpa awak. Bahasa pemrograman yang digunakan adalah bahasa pyton yang didalamnya sudah berjalan Web Server Apache. Sehingga dengan perancangan prototype robot cerdas pemotongan rumput berbasis rasbery Pi B+ menggunakan web browser pada saat rumput sudah mulai tumbuh tinggi, robot cerdas pemotong rumput dapat dengan langsung melakukan pemotongan rumput dengan dikendalikan web browser.
\end{abstract}

\section{Kata Kunci : Robot, Raspberry Pi, Python, Web Browser}

\begin{abstract}
Current science and technology are developing by leaps and bounds thus providinggreat benefits in all aspects of human life including the robot-a robot designed toassist human tasks through supervision and human control, or use the program. The development of grass that propagate ground quickly often make nursing groundshave to mow the lawn with regular intensive. Related to this, then the tool in the form of a single intelligent robot cutting grass-based Pi B+ raspberry is the application ofrobotic systems that aim to control 2 motor Driver 1298 n useful for running gear boxwheel robots and grass cutters on Dynamo cutting tools lawns without a crew. The programming language used is the language which has been running pyton Apache Web Server. So by designing Intelligent robot prototype lawnmowing rasbery Pibased B+ using a web browser at the time grass has begun to grow tall, grass-cuttingIntelligent robot can directly perform cutting grass with a controlled web browser.
\end{abstract}

\section{Keywords : Robot, Raspberry Pi, Python, Web Browser}

Vol.1 No.1 - Agustus 2015 


\section{PENDAHULUAN}

Rumput adalah tanaman yang paling umum digunakan sebagai penutup permukaan taman. Hal ini sangat mudah dipahami karena rumput mampu memberikan kesan lebih asri dan hijau pada taman. Selain itu, penggunaan rumput juga akan meminimalisir munculnya debu akibat tanah yang kering. Sifat rumput yang sangat baik dalam menyerap air sehingga rumput juga merupakan alternatif yang baik untuk menghindari genangan air di musim hujan.

Keindahan suatu taman sangat bergantung pada bagaimana teknik perawatan taman tersebut. Untuk mendapatkan taman yang indah dipandang mata, maka pemotongan rumput dilakukan secara teratur. Secara umum, perawatan taman masih mengandalkan sumber daya manusia untuk memotong rumput yang merambat menutup tanah. Sering kali rumput yang tumbuh disekitaran kebun kita sangat cepat tumbuh, sehingga kegiatan pemotongan rumput menjadi beban bagi pekerja kebersihan.

Seiring dengan pesatnya perkembangan ilmu pengetahuan dan teknologi saat ini memberikan manfaat besar dalam segala aspek kehidupan manusia. Hal ini dapat dilihat dari pembuatan robot - robot cerdas dan otomatis yang merupakan tuntutan dari dunia industri modern, menuntut adanya suatu alat berkemampuan tinggi sehingga dapat menyelesaikan pekerjaan manusia dengan hasil maksimal.

\section{LANDASAN TEORI}

\section{Definisi Prototipe}

Menurut Simarmata (2010:62), "Prototype adalah bagian dari produk yang mengekspresikan logika maupun fisik antarmuka eksternal yang ditampilkan".

Menurut Wiyancoko (2010:120), "Prototype" adalah model produk yang mewakili hasil produksi yang sebenarnya".

Dari pendapat yang

dikemukakan di atas dapat disimpulkan bahwa "prototype" adalah proses pembuatan model produk dalam sebuah perancangan.

\section{Jenis-Jenis Prototipe}

Jenis-jenis Prototype secara general dibagi menjadi dua, yaitu:

(Simarmata, 2010:64)

\section{a. Rapid Throwaway Prototyping}

Pendekatan pengembangan

perangkat keras/Iunak ini dipopulerkan oleh Gomaa dan Scoot (1981) yang saat ini telah digunakan secara luas oleh industri, terutama di dalam pengembangan aplikasi. Pendekatan ini biasanya digunakan dengan item yang berisiko tinggi (high-risk) atau dengan bagian dari sistem yang tidak dimengerti secara keseluruhan oleh para tim pengembang. Pada pendekatan ini, Prototype "quick and dirty" dibangun, diverifikasi oleh kansumen, dan dibuang hingga Prototype yang diinginkan tercapai pada saat proyek berskala besar dimulai.

\section{b. Prototype Evolusioner}

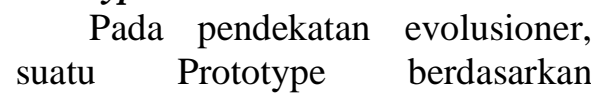
kebutuhan dan pemahaman secara umum.Prototype kemudian diubah dan dievolusikan daripada dibuang.Prototype yang dibuang biasanya digunakan dengan aspek sistem yang dimengerti secara luas dan dibangun atas kekuatan tim 
pengembang. Prototype ini juga didasarkan atas kebutuhan prioritas, kadang-kadang diacu sebagai "chunking" pada pengembang aplikasi (Hough, 1993).

\section{Definisi Robot}

Menurut Beni Anggoro (2013), Robot berasal dari kata "robota" yang dalam bahasa Ceko yang berarti budak, pekerja atau kuli. Pertama kali kata "robota" diperkenalkan oleh Karel Capek dalam sebuah pentas sandiwara pada tahun 1921 yang berjudul RUR (Rossum's Universal Robot) ${ }^{[2]}$. Pentas ini mengisahkan mesin yang menyerupai manusia yang dapat bekerja tanpa lelah yang kemudian memberontak dan menguasai manusia. Istilah "robot" ini kemudian mulai terkenal dan digunakan untuk menggantikan istilah yang dikenal saat itu yaitu automation. Dari berbagai litelatur robot dapat didefinisikan sebagai sebuah alat mekanik yang dapat diprogram berdasarkan informasi dari lingkungan (melalui sensor) sehingga dapat melaksanakan beberapa tugas tertentu baik secara otomatis ataupun tidak sesuai program yang di inputkan berdasarkan logika.

\section{Definisi Raspberry Pi} (2014),

Menurut John wiley \& Sons Ltd

"The Raspberry Pi is a credit sized computer that plug into your TV and a keyboard. It is a capable little computer which can be used in electronics prjocects, and for many things that your desktop PC does, like spreadsheets,word-processing and games. It also plays high definiton video."

“ Raspberry Pi adalah sebuah komputer berukuran sebesar kartu kredit yang terhubung ke televisi dan sebuah keyboard. Komputer kecil ini bisa digunakan untuk proyek-proyek elektronik dan hal lainnya yang bisa dilakukan oleh desktop komputer seperti sebagai mesin pengolah kata, games dan perangkat ini juga mampu memainkan video beresolusi tinggi".

\section{Raspberry Pi B+}

"The Raspberry Pi 2 Model B is the second generation Raspberry Pi. It replaced the original Raspberry Pi 1 Model B+ in February 2015”.

"Raspberry Pi 2 Model B adalah generasi kedua Raspberry Pi. Ia menggantikan Model Raspberry Pi 1 Model B + pada bulan Februari 2015".

Sumber:www.raspberrypi.org.Diambilda ri: https://www.raspberrypi.org/products /raspberry-pi-2-model-b/. (Tanggal akses 14 April 2015).

"The Model B+ is the final revision of the original Raspberry Pi. It replaced the Model B in July 2014 and was superseded by the Raspberry Pi 2 Model B in February 2015”.

" Model B + adalah revisi akhir asli Raspberry Pi. Ia menggantikan Model B pada bulan Juli 2014 dan digantikan oleh Raspberry Pi Model B 2 di Februari 2015".

Sumber: www.raspberrypi.org. Diambil dari: https://www.raspberrypi.org/produ cts/model-b-plus/. (Tanggal akses 14 April 2015).

Dari pengertian di atas bisa di liat bahwa Raspberry Pi B+ adalah generasi kedua dari Raspberry itu sendiri yang telah di Perbaharui di berbagai sector antara lain adalah 


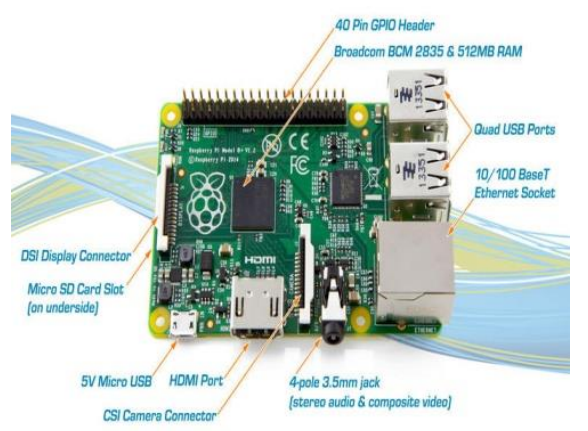

Gambar 1. Raspberry Pi B+

\section{Konsep Dasar Phyton}

Pada awalnya, motivasi pembuatan bahasa pemrograman ini adalah untuk bahasa skrip tingkat tinggi pada sistem operasi terdistribusi Amoeba. Bahasa pemrograman ini menjadi umum digunakan untuk kalangan engineer seluruh dunia dalam pembuatan perangkat lunaknya, bahkan beberpa perusahaan menggunakan python sebagai pembuat perangkat lunak komersial. Python merupakan bahasa pemrograman yang freeware atau perangkat bebas dalam arti sebenarnya, tidak ada batasan dalam penyalinannya atau mendistribusikannya. Lengkap dengan source codenya, debugger dan profiler, antarmuka yang terkandung di dalamnya untuk pelayanan antarmuka, fungsi sistem, GUI (antarmuka pengguna grafis), dan basis datanya.

Python dikembangkan oleh Guido van Rossum pada tahun 1990 di CWI, Amsterdam sebagai kelanjutan dari bahasa pemrograman ABC. Versi terakhir yang dikeluarkan CWI adalah 1.2. Tahun 1995, Guido pindah ke CNRI sambil terus melanjutkan pengembangan Python. Versi terakhir yang dikeluarkan adalah 1.6. Tahun 2000, Guido dan para pengembang inti Python pindah ke
- GPIO pada Model B+ kini menjadi 40 pin.

- 4 Port USB 2.0.

- Soket SD Card yang diperbarui.

- Konsumsi daya yang lebih hemat, sekitar 0.5 - 1 Watt lebih hemat

- Chip Audio yang diperbarui dengan anti-noise.

- Penggeseran tata letak beberapa port.

BeOpen.com yang merupakan sebuah perusahaan komersial dan membentuk BeOpen PythonLabs. Python 2.0 dikeluarkan oleh BeOpen. Setelah mengeluarkan Python 2.0, Guido dan beberapa anggota tim PythonLabs pindah ke DigitalCreations. Saat ini pengembangan Python terus dilakukan oleh sekumpulan pemrogram yang dikoordinir Guido dan Python Software Foundation. Python Software Foundation adalah sebuah organisasi non-profit yang dibentuk sebagai pemegang hak cipta intelektual Python sejak versi 2.1 dan dengan demikian mencegah Python dimiliki oleh perusahaan komersial. Saat ini distribusi Python sudah mencapai versi 2.6.1 dan versi 3.0. Nama Python dipilih oleh Guido sebagai nama bahasa ciptaannya karena kecintaan guido pada acara televisi Monty Python s Flying Circus. Oleh karena itu seringkali ungkapanungkapan khas dari acara tersebut seringkali muncul dalam korespondensi antar pengguna Python. Aplikasi bahasa phyton Perangkat bantu shell. Tugastugas sistem administrator, program baris perintah. Kerja bahasa ekstensi. Antarmuka untuk pustaka $\mathrm{C} / \mathrm{C}++$.

Sumber : Triasanti,

Dini.2012.Universitas Gunadarma.

Diambil dari: 
http://dini3asa.staff.gunadarma.ac.id. (Tanggal akses 13 April 2015).

\section{Definisi Web Browser}

Web Browser adalah suatu program atau software yang digunakan untuk menjelajahi internet atau untuk mencari informasi dari suatu web yang tersimpan didalam komputer. Awalnya, web browser berorientasi pada teks dan belum dapat menampilkan gambar. Namun, web browser sekarang tidak hanya menampilkan gambar dan teks saja, tetapi juga memutar file multimedia seperti video dan suara. Web browser juga dapat mengirim dan menerima email, mengelola HTML, sebagai input dan menjadikan halaman web sebagai hasil output yang informative. Dengan menggunakan web browser, para pengguna internet dapat mengakses berbagai informasi yang terdapat di internet dengan mudah. Beberapa contoh web browser diantaranya Internet Explorer, Mozilla, Firefox, Safari, Opera, dll.

Sumber: Rahma. 2013. Web

Browser

dari: http://rahma099c.blogspot.com/

(Tanggal akses 15 April 2015).

\section{Literature Riview}

Berikut ini adalah penelitian yang telah dilakukan dan memiliki kolerasi yang searah dengan penelitian yang akan dibahas dalam Jurnal ini diantara lain:

1. Penelitian yang telah dilakukan oleh Haerul Nurdiana dari STMIK RAHARJA sebagai bentuk Tugas Kuliah Kerja Praktek dengan judul "Pemantauan Ruang Komputer Menggunakan Komputer Mini Raspberry $P i \quad B \quad P a d a$ SMPN 1 Pasarkemis". Pada tugas kuliah kerja praktek ini penulis bertujuan untuk memantau ruang komputer secara real time menggunakan raspberry dan komponen USB Webcam.

2. Penelitian yang telah dilakukan oleh Abdul Rohman Rasyid dan Rani Puspita Fauzi dari Universitas Sumatra Utara sebagai bentuk Jurnal Penelitian Ilmiah dengan judul "Robot Cinung Pemotong Rumput dan Penyapu Halaman" . Pada penelitian ini penulis bertujuan untuk melakukan terobosan baru dengan membuat sistem otomatisasi yang dapat meringankan pekerjaan manusia. Dengan menggunakan limit switch, relay, motor DC dan mikrokontroller jenis AT89C51 dengan Flash Programmable produksi ATMEL.

3. Penelitian yang telah dilakukan oleh Fauzi Arizal dari Universitas Gunadarma sebagai bentuk Skripsi dengan judul "Pengendali Robot Pemotong Rumput Melalui Android dengan Bluetooth berbasis Arduino". Pada penelitian ini peneliti bertujuan untuk mempermudah pekerjaan manusia dengan membuat robot pemotong rumput menggunakan gearbox motor DC yang ditempatkan pada posisi belakang robot . Sedangkan untuk antar muka dengan pengguna, penulis menggunakan software eclipse untuk membuat aplikasi pengendali robot. Komunikasi antara robot beroda dengan smartphone melalui media komunikasi Bluetooth.

4. Penelitian yang dilakukan oleh Arfa dari STMK Raharja Tangerang dengan judul "Akses Kontrol Kendaraan Bermotor Roda Empat Menggunakan Password dan Sensor Infrared Berbasis Mikrokontroller ATMega328". Pada penelitian ini penulis bertujuan untuk mengakses dan mengontrol kendaraan dengan menggunakan metode password 
akses dan sensor inframerah sebagi pendeteksi objek yang berbasis mikrokontroller ATMega328 dengan komponen motor DC L239D.

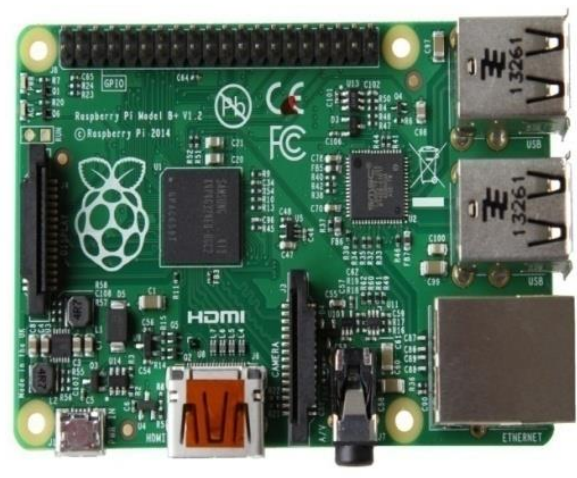

Gambar 2. Raspberry Pi B+

Raspberry $\mathrm{Pi} \mathrm{B}+$ adalah sebuah Personal Computer (PC) yang berukuran sebesar kartu ATM. Raspberry Pi B+ memiliki system on a chip (SoC) bernama BCM2835, memiliki Processor ARM1176JZ 700MHz dan RAM 512 MB. Beberapa Port dan Slot pada Raspberry $\mathrm{Pi} \mathrm{B}+$ :

1. Micro (SD) Card Slot Slot ini digunakan untuk penyimpanan OS yang telah diinstal pada micro SD.

2. Universal Serial Bus (USB) Port

Pada Raspberry Pi B+ terdapat 4 Port USB 2.0 biasanya dipakai untuk Mouse dan Keyboard.

\section{Ethernet Port}

Terdapat port RJ45 standar yang dapat terhubung pada jaringan.

\section{PEMBAHASAN}

Perancangan Perangkat Keras (Hardware)

\section{Rangkaian Raspberry Pi B+}

4. High Definition

Multimedia Interface

(HDMI) Konektor Berfungsi untuk menampilkan gambar digital dari Raspberry kelayar Monitor.

5. Output Audio / RCA Mini

Terdapat jack standar $3.5 \mathrm{~mm}$ yang berfungsi untuk menghasilkan suara.

\section{Power Input}

Terdapat microUSB konektor yang berfungsi untuk supply listrik pada Raspberry PI B+.

7. Status LEDs

Tabel 1. Status LED

\begin{tabular}{|l|l|l|}
\hline PWR & MERAH & $\begin{array}{l}\text { Terhubung } \\
\text { ke arus } \\
\text { listrik 5V }\end{array}$ \\
\hline ACT & HIJAU & $\begin{array}{l}\text { Lampu } \\
\text { menyala } \\
\text { ketika } \\
\text { micro sd } \\
\text { diakses }\end{array}$ \\
\hline
\end{tabular}

Sumber : (Matt Richardson dan Shawn Wallace 2013 : 4)

Beberapa Fungsi Pin pada Raspberry Pi B+ :

1. General Purpose Input and Output (GPIO)

Digunakan untuk membaca tombol dan switch kontrol seperti pada LED, relay atau pun motor. 
Tabel 2. Pin GPIO

\begin{tabular}{|r|c|r|r|l|r|}
\hline & & Pin & Pin & & \\
\hline $3.3 \mathrm{v}$ & $\leftarrow$ & 1 & 2 & $\rightarrow$ & $5 \mathrm{~V}$ \\
\hline GPIO0 & $\leftarrow$ & 3 & 4 & $\rightarrow$ & $5 \mathrm{v}$ \\
\hline GPIO1 & $\leftarrow$ & 5 & 6 & $\rightarrow$ & Ground \\
\hline GPIO4 & $\leftarrow$ & 7 & 8 & $\rightarrow$ & GPIO14 \\
\hline Ground & $\leftarrow$ & 9 & 10 & $\rightarrow$ & GPIO15 \\
\hline GPIO17 & $\leftarrow$ & 11 & 12 & $\rightarrow$ & GPIO18 \\
\hline GPIO21 & $\leftarrow$ & 13 & 14 & $\rightarrow$ & Ground \\
\hline GPIO22 & $\leftarrow$ & 15 & 16 & $\rightarrow$ & GPIO23 \\
\hline $3.3 v$ & $\leftarrow$ & 17 & 18 & $\rightarrow$ & GPIO24 \\
\hline GPIO10 & $\leftarrow$ & 19 & 20 & $\rightarrow$ & Ground \\
\hline GPIO9 & $\leftarrow$ & 21 & 22 & $\rightarrow$ & GPIO25 \\
\hline GPIO11 & $\leftarrow$ & 23 & 24 & $\rightarrow$ & GPIO8 \\
\hline Ground & $\leftarrow$ & 25 & 26 & $\rightarrow$ & GPIO7 \\
\hline ID_SD & $\leftarrow$ & 27 & 28 & $\rightarrow$ & ID_SC \\
\hline GPIO05 & $\leftarrow$ & 29 & 30 & $\rightarrow$ & Ground \\
\hline GPIO06 & $\leftarrow$ & 31 & 32 & $\rightarrow$ & Gpio12 \\
\hline GPIO13 & $\leftarrow$ & 33 & 34 & $\rightarrow$ & Ground \\
\hline GPIO19 & $\leftarrow$ & 35 & 36 & $\rightarrow$ & GPIO16 \\
\hline GPIO26 & $\leftarrow$ & 37 & 38 & $\rightarrow$ & GPIO20 \\
\hline Ground & $\leftarrow$ & 39 & 40 & $\rightarrow$ & GPIO21 \\
\hline
\end{tabular}

Sumber : (Maik Schmidt 2012 : 89)

2. Display Serial Interface (DSI) Konektor

Konektor ini menerima 15 pin kabel pita yang dapat digunakan untuk berkomunikasi dengan LCD atau OLED.

3. Camera Serial Interface (CSI) Konektor

Port ini memungkinkan kamera modul untuk dihubungkan langsung ke board Raspberry.

4. $\mathrm{P} 2$ dan $\mathrm{P} 3$

Kedua baris digunakan pengujian JTAG untuk chip Broadcom (P2) dan chip jaringan LAN9512 (P3).

\section{Wireless USB}

\begin{tabular}{lr}
\multicolumn{1}{c}{ Tp-Link } & WN722N \\
berfungsi & untuk \\
menghubungkan & jaringan \\
nirkabel Raspberry. & TP-Link \\
WN722N mampu memberikan \\
kecepatan nirkabel & hingga \\
150Mbps. &
\end{tabular}

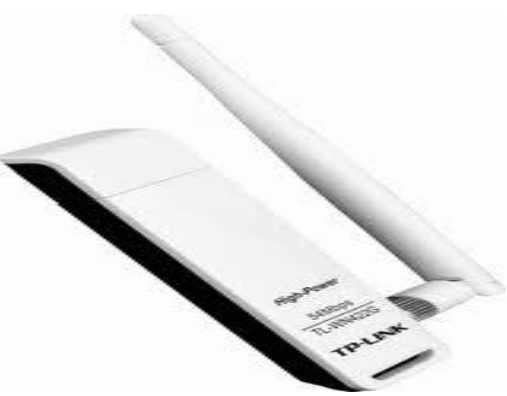

Sumber: (http://www.tplink.com/en/products/details/?mode l=tl-wn722n)

\section{Gambar 3. Tp-Link WN722N}

\section{Perancangan Perangkat Lunak (Software)}

\section{Installasi Web IOPi}

WebIOPi

adalah aplikasi open source yang dibuat untuk membuat mengontrol GPIO melalui web browser. Aplikasi ini merupakan framework untuk bahasa pemrograman python yang didalamnya sudah berjalan WebServer Apache.

Untuk mengetahui dimana file WebIOPi disimpan di raspberry maka masukan perintah : pi@raspberrypi\$cd WebIOPi-0.7.0 
Berikut gambar yang dihasilkan

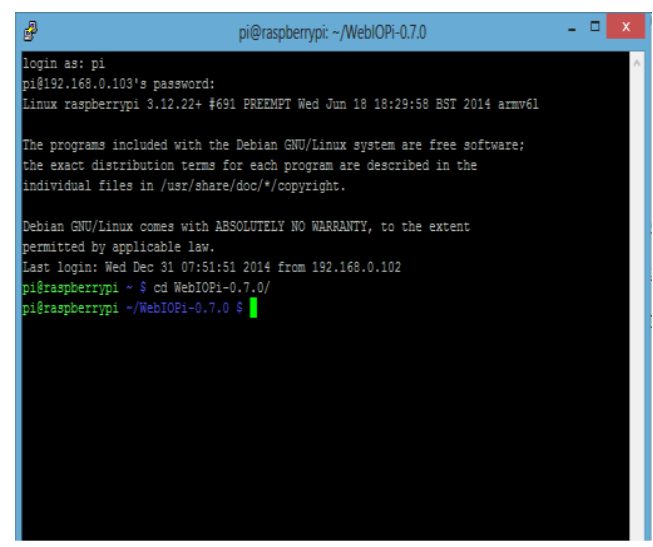

Gambar 4. Direktori Web IOPi

\section{Menampilkan Direktori Program}

Untuk menampilkan direktori Program di dalam Raspberry maka masukan perintah : pi@raspberrypi\$cd poton

Berikut gambar yang dihasilkan :

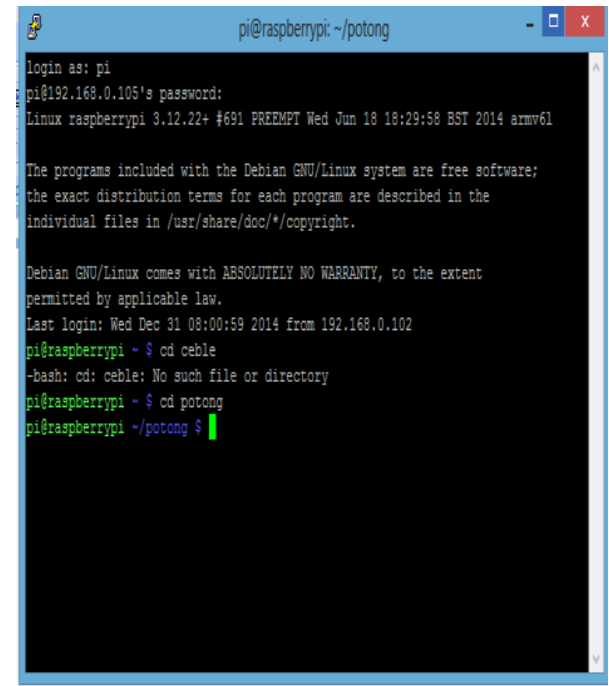

Gambar 5. Direktori Program

\section{Membuat Program bahasa Python}

Untuk membuat program yang akan dijalankan didalam raspberry :
pi@raspberrypi\$ sudo nano ceble.py

Berikut gambar yang dihasilkan

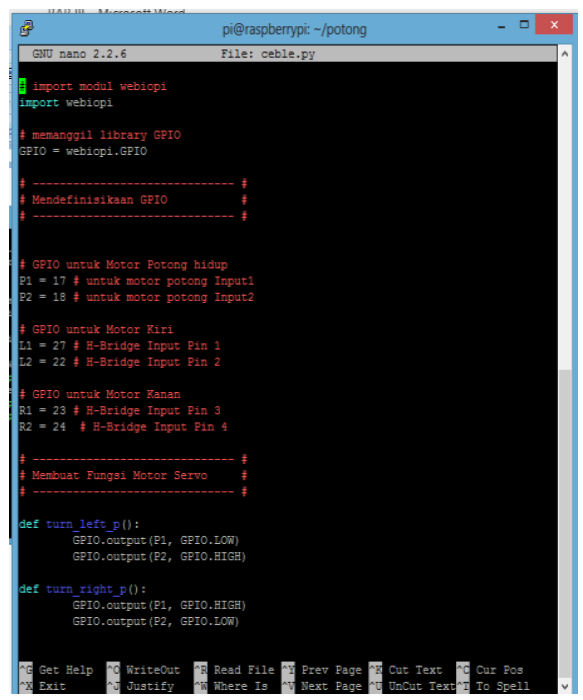

Gambar 6. Program Python

\section{Menjalankan Program}

Untuk menjalankan program robot ini haruslah diberi perintah sebagai berikut :

pi@raspberrypi ／potong \$ sudo python ceble.py

Berikut gambar yang dihasilkan 


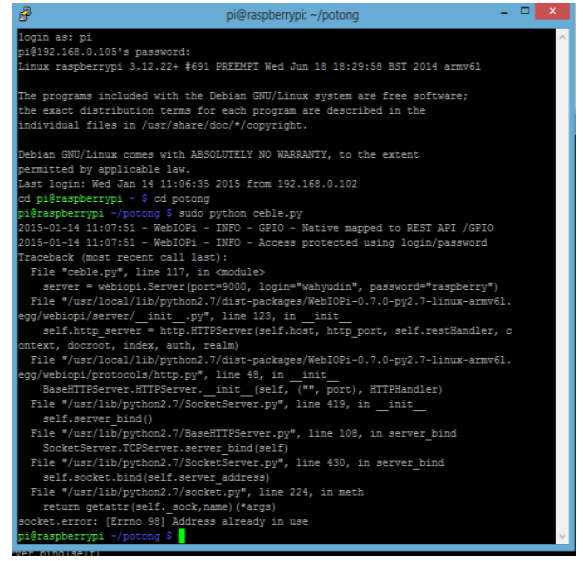

Gambar 7. Proses Menjalankan Program Python

\section{Tampilan Web Browser}

setelah program berjalan dengan baik untuk mengoprasikan program robot ini secara real maka dapat langsung diopresaikan dengan membuka web browser dengan alamat ip sebagai berikut

192.168.43.145:9000

Berikut gambar yang dihasilkan

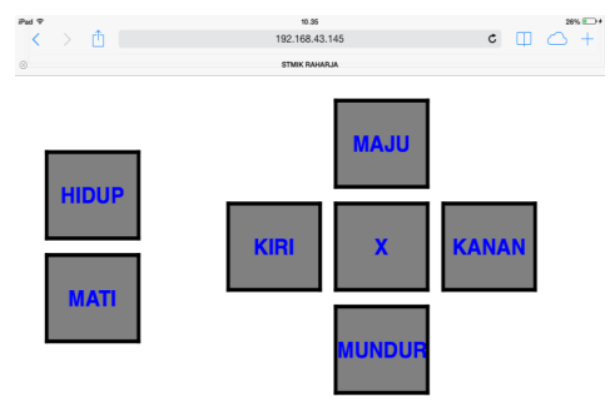

Gambar 8. Tampilan Web

\section{Kesimpulan}

Setelah mengadakan penelitian dan mencoba memecahkan masalah yang ada, maka dapat disimpulkan bahwa prototipe robot cerdas pemotong rumput dirancang dengan menggunakan

\section{Keterangan :}

Button Hidup : untuk menghidupkan dinamo pemotong.

Button Mati : untuk mematikan dinamo pemotong.

Button Maju :untuk menjalankan roda maju.

Button Mundur : untuk menjalankan roda mundur.

Button Kiri : untuk membelokan roda ke kiri.

Button Kanan : untuk membelokan roda ke kanan.

Button X : untuk menormalkan gerak robot.

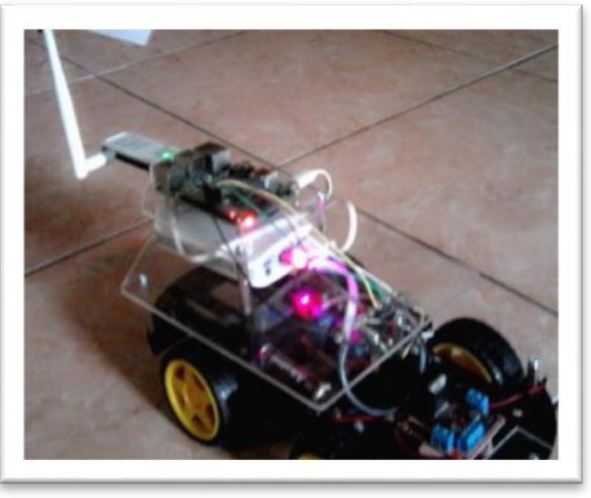

Gambar 8. Tampilan Robot

raspberry b+ yang di program menggunakan bahasa pemograman python. Untuk menggerakan robot pemotong rumput raspberry pi b+ memberikan perintah kepada motor driver agar dapat mejalankan gear box roda. dan Prototipe robot cerdas pemotong rumput taman ini dapat 
dikontrol melalui browser pada semua device elektronik, baik semua smartphone, pc/laptop dan ipad yang terhubung dalam satu jaringan. Ketika rumput sudah mulai tumbuh tinggi robot pemotong rumput dapat dengan langsung melakukan pemotongan rumput dengan dikendalikan melalui web browser.

\section{DAFTAR PUSTAKA}

1. Beni Anggoro(2013). Desain Pemodelan Kinematik Dan Dinamik Humanoid Robot, pada Universitas DiPonegoro semarang.

2. John wiley \& Sons Ltd. 2014. "Adventure in Raspberry Pi". United Kindom

3. Mall, Fundamental of Sotware Engineering, NewDelhi: RajkamalElectris Press.2009.

4. Rahma. 2013. Web Browser dari: http://rahma099c.blogspot.com/ (Tanggal akses 15 April 2015).

5. RASPBERRY PI 2 MODEL B. dari : https://www.raspberrypi.org/products/ras pberry-pi-2-model-b/ (Tanggal Akses 14 April 2015)

6. Raspberrypi.org .2015. RASPBERRY PI 1 MODEL B+. dari : https://www.raspberrypi.org/products/mo del-b-plus/ (Tanggal Akses 14 April 2015).

7. Simarmata,Janner. 2010. Rekayasa Perangkat Lunak. Yogyakarta: ANDI.

8. Triasanti, Dini. 2012. Universitas Gunadarma. Diambil dari: dini3asa.staff.gunadarma.ac.id. (Tanggal akses 14 April 2015).

9. Wiyancoko, Dudy. 2010. “"Desain Sepeda Indonesia"'. Jakarta: PT. Dumedia Desain. 